\title{
Classifications of solutions of second-order nonlinear neutral differential equations of mixed type
}

\author{
E Thandapani ${ }^{1}$, S Padmavathi ${ }^{1}$ and S Pinelas ${ }^{2 *}$
}

\author{
"Correspondence: \\ sandra.pinelas@gmail.com \\ ${ }^{2}$ Departamento de Ciências Exactas \\ e Naturais, Academia Militar, Av. \\ Conde Castro Guimarães, Amadora, \\ 2720-113, Portugal \\ Full list of author information is \\ available at the end of the article
}

\begin{abstract}
In this paper the authors classified all solutions of the second-order nonlinear neutral differential equations of mixed type,

$$
\left(a(t)\left(x(t)+b x\left(t-\tau_{1}\right)+c x\left(t+\tau_{2}\right)\right)^{\prime}\right)^{\prime}+p(t) x^{\alpha}\left(t-\sigma_{1}\right)+q(t) x^{\beta}\left(t+\sigma_{2}\right)=0,
$$

into four classes and obtained conditions for the existence/non-existence of solutions in these classes. Examples are provided to illustrate the main results.
\end{abstract}

MSC: $34 \mathrm{C} 15$

Keywords: oscillation; second order; neutral differential equation; mixed type

\section{Introduction}

This paper is concerned with the second-order nonlinear neutral differential equations of mixed type of the form

$$
\left(a(t)\left(x(t)+b x\left(t-\tau_{1}\right)+c x\left(t+\tau_{2}\right)\right)^{\prime}\right)^{\prime}+p(t) x^{\alpha}\left(t-\sigma_{1}\right)+q(t) x^{\beta}\left(t+\sigma_{2}\right)=0,
$$

$t \geq t_{0}>0$, subject to the following conditions:

(c $\left.c_{1}\right) a \in C^{1}\left(\left[t_{0}, \infty\right), \mathbb{R}\right)$ and is positive for all $t \geq t_{0}$;

$\left(\mathbf{c}_{2}\right) \quad b$ and $c$ are constants; $\tau_{1}, \tau_{2}, \sigma_{1}$ and $\sigma_{2}$ are nonnegative constants;

(c) $\alpha$ and $\beta$ are the ratio of odd positive integers;

$\left(\mathrm{c}_{4}\right) \quad p, q \in C\left(\left[t_{0}, \infty\right), \mathbb{R}\right)$.

By a solution of equation (1.1), we mean a function $x \in C\left(\left[T_{x}, \infty\right), \mathbb{R}\right)$ for some $T_{x} \geq t_{0}$, which has the properties $x(t)+b x\left(t-\tau_{1}\right)+c x\left(t+\tau_{2}\right) \in C^{1}\left(\left[T_{x}, \infty\right), \mathbb{R}\right)$ and $a(t)(x(t)+b x(t-$ $\left.\left.\tau_{1}\right)+c x\left(t+\tau_{2}\right)\right) \in C^{1}\left(\left(T_{x}, \infty\right), \mathbb{R}\right)$ and satisfies equation (1.1) on [ $\left.T_{x}, \infty\right)$. As is customary, a solution of equation (1.1) is oscillatory if it is neither eventually positive nor eventually negative; otherwise, it is called non-oscillatory. A non-oscillatory solution $x(t)$ of equation (1.1) is said to be weakly oscillatory if $x(t)$ is non-oscillatory and $x^{\prime}(t)$ is oscillatory for large value of $t$.

Second-order neutral delay differential equations have applications in problems dealing with vibrating masses attached to an elastic and also appear, as the Euler equation, in some vibrational problems (see [1] and [2]).

\section{Springer}

(c) 2012 Thandapani et al.; licensee Springer. This is an Open Access article distributed under the terms of the Creative Commons Attribution License (http://creativecommons.org/licenses/by/2.0), which permits unrestricted use, distribution, and reproduction in any medium, provided the original work is properly cited. 
In [3] the authors considered equation (1.1) with $q(t)=0, b=h(t), c=0$ and $\alpha=1$ for all $t \geq t_{0}$, and classified all solutions of (1.1) into four classes and obtained criteria for the existence/non-existence of solutions in these classes. In [4] the authors considered equation (1.1) with $q \leq 0, b=c(t), c=0, \alpha=1, \beta=1$ for all $t \geq t_{0}$, and classified all solutions into four classes and obtained the solutions in these classes. For $p(t)=0$ or $q(t)=0$ and $c=0$ for all $t \geq t_{0}$, the oscillatory and asymptotic behavior of solutions of equation (1.1) is discussed in [5, 6] and [7].

In [8-12] the authors considered equation (1.1) with $a(t) \equiv 1, \alpha=\beta=1$ or $\alpha=\beta$ and obtained conditions for the oscillation of all solutions of equation (1.1). Motivated by this observation, in this paper we consider the cases $p, q \geq 0$ and $p, q$ changes sign for all large $t$, to give sufficient conditions in order that every solution of equation (1.1) is either oscillatory or weakly oscillatory and to study the asymptotic nature of non-oscillatory solutions of equation (1.1) with respect to their asymptotic behavior. All the solutions of equation (1.1) may be a priori divided into the following classes:

$$
\begin{aligned}
& M^{+}=\left\{x=x(t) \text { solution of }(1.1) \text { : there exists } t_{x} \geq t_{0} \text { such that } x(t) x^{\prime}(t) \geq 0, t \geq t_{x}\right\}, \\
& M^{-}=\left\{x=x(t) \text { solution of }(1.1) \text { : there exists } t_{x} \geq t_{0} \text { such that } x(t) x^{\prime}(t) \leq 0, t \geq t_{x}\right\}, \\
& O S=\left\{x=x(t) \text { solution of }(1.1): \text { there exists }\left\{t_{n}\right\}, t_{n} \rightarrow \infty \text { such that } x\left(t_{n}\right)=0\right\}, \\
& W O S=\left\{x=x(t) \text { solution of }(1.1) x(t) \neq 0 \text { for all large } t \text { but } x^{\prime}(t) \text { oscillates }\right\} .
\end{aligned}
$$

In Section 2, we obtain sufficient conditions for the existence/non-existence in the above said classes. In Section 3, we discuss the asymptotic behavior of solutions in the solutions $M^{+}$and $M^{-}$. Examples are provided to illustrate the main results.

\section{Existence results}

First, we examine the existence of solutions of equation (1.1) in the class $M^{+}$.

Theorem 2.1 With respect to the differential equation (1.1), assume that

$\left(\mathrm{H}_{1}\right) \quad b \geq 0$ and $c \geq 0$;

$\left(\mathrm{H}_{2}\right) \quad p(t) \geq 0$ for all $t \geq t_{0}$;

$\left(\mathrm{H}_{3}\right) \alpha>\beta$ and $\sigma_{1} \leq \sigma_{2}$.

If

$$
\limsup _{t \rightarrow \infty} \int_{t_{0}}^{t}(L p(s)+q(s)) d s=\infty
$$

for every $L>0$, then $M^{+}=\emptyset$.

Proof Suppose that equation (1.1) has a solution $x \in M^{+}$. Without loss of generality, we may assume that there exists $t_{1} \geq t_{0}$ such that $x(t)>0$ and $x^{\prime}(t) \geq 0$ for all $t \geq t_{1}$. (The proof if $x(t)<0$ and $x^{\prime}(t) \leq 0$ is similar for large $t$.) Let $z(t)=x(t)+b x\left(t-\tau_{1}\right)+c x(t+$ $\left.\tau_{2}\right)$ for $t \geq t_{1}$. Then by assumption $\left(\mathrm{H}_{1}\right)$ we have $z(t)>0$ and $z^{\prime}(t) \geq 0$ for all $t \geq t_{1}$. 
Now,

$$
\begin{aligned}
\left(\frac{a(t) z^{\prime}(t)}{x^{\beta}\left(t-\sigma_{2}\right)}\right)^{\prime} & =\frac{\left(a(t) z^{\prime}(t)\right)^{\prime}}{x^{\beta}\left(t-\sigma_{2}\right)}-\frac{\beta a(t) z^{\prime}(t) x^{\prime}\left(t-\sigma_{2}\right)}{x^{\beta+1}\left(t-\sigma_{2}\right)} \\
& \leq-p(t) \frac{x^{\alpha}\left(t-\sigma_{1}\right)}{x^{\beta}\left(t-\sigma_{2}\right)}-q(t) \\
& \leq-p(t) \frac{x^{\alpha}\left(t-\sigma_{2}\right)}{x^{\beta}\left(t-\sigma_{2}\right)}-q(t) \\
& \leq-p(t) x^{\alpha-\beta}\left(t-\sigma_{2}\right)-q(t), \quad t \geq t_{1} .
\end{aligned}
$$

Since $x(t)>0$ and $x^{\prime}(t) \geq 0$, we have $x(t) \geq L_{0}>0$ and by $\left(\mathrm{H}_{3}\right), x^{\alpha-\beta}(t) \geq L>0$ for all $t \geq t_{1} \geq t_{2}$. Thus

$$
\left(\frac{a(t) z^{\prime}(t)}{x^{\beta}\left(t-\sigma_{2}\right)}\right)^{\prime} \leq-(L p(t)+q(t)), \quad t \geq t_{2}
$$

Integrating the last inequality from $t_{2}$ to $t$, we obtain

$$
\frac{a(t) z^{\prime}(t)}{x^{\beta}\left(t-\sigma_{2}\right)}-\frac{a\left(t_{2}\right) z^{\prime}\left(t_{2}\right)}{x^{\beta}\left(t_{2}-\sigma_{2}\right)} \leq-\int_{t_{2}}^{t}(L p(s)+q(s)) d s
$$

From condition (2.1), we obtain

$$
\liminf _{t \rightarrow \infty} \frac{a(t) z^{\prime}(t)}{x^{\beta}\left(t-\sigma_{2}\right)}=-\infty
$$

which contradicts the fact that $z^{\prime}(t) \geq 0$ for all large $t$. This completes the proof of the theorem.

Theorem 2.2 Assume that condition $\left(\mathrm{H}_{1}\right)$ holds. Further assume that

$\left(\mathrm{H}_{4}\right) \quad q(t) \geq 0$ for all $t \geq t_{0}$

$\left(\mathrm{H}_{5}\right) \beta>\alpha$.

If

$$
\limsup _{t \rightarrow \infty} \int_{t_{0}}^{t}\left(p(s)+L_{1} q(s)\right) d s=\infty
$$

for every $L_{1}>0$, then $M^{+}=\emptyset$.

Proof Suppose that equation (1.1) has a solution $x \in M^{+}$. Without loss of generality, we may assume that there exists $t_{1} \geq t_{0}$ such that $x(t)>0$ and $x^{\prime}(t) \geq 0$ for all $t \geq t_{1}$. (The proof is similar if $x(t)<0$ and $x^{\prime}(t) \leq 0$ for large $t$.) Let $z(t)=x(t)+b x\left(t-\tau_{1}\right)+c x\left(t+\tau_{2}\right)$ for $t \geq t_{1}$. Then by assumption $\left(\mathrm{H}_{1}\right)$ we have $z(t)>0$ and $z^{\prime}(t) \geq 0$ for all $t \geq t_{1}$. Now,

$$
\begin{aligned}
\left(\frac{a(t) z^{\prime}(t)}{x^{\alpha}\left(t-\sigma_{1}\right)}\right)^{\prime} & =\frac{\left(a(t) z^{\prime}(t)\right)^{\prime}}{x^{\alpha}\left(t-\sigma_{1}\right)}-\frac{\alpha a(t) z^{\prime}(t) x^{\prime}\left(t-\sigma_{1}\right)}{x^{\alpha+1}\left(t-\sigma_{1}\right)} \leq-p(t)-q(t) \frac{x^{\beta}\left(t+\sigma_{2}\right)}{x^{\alpha}\left(t-\sigma_{1}\right)} \\
& \leq-p(t)-q(t) x^{\beta-\alpha}\left(t-\sigma_{1}\right), \quad t \geq t_{1} .
\end{aligned}
$$


As in the proof of Theorem 2.1, we have $x^{\beta-\alpha}\left(t-\sigma_{1}\right) \geq L_{1}>0$ for $t \geq t_{2} \geq t_{1}$ by condition $\left(\mathrm{H}_{5}\right)$. Thus

$$
\left(\frac{a(t) z^{\prime}(t)}{x^{\alpha}\left(t-\sigma_{1}\right)}\right)^{\prime} \leq-\left(p(t)+L_{1} q(t)\right), \quad t \geq t_{2}
$$

Integrating the last inequality from $t_{2}$ to $t$, we have

$$
\frac{a(t) z^{\prime}(t)}{x^{\alpha}\left(t-\sigma_{1}\right)}-\frac{a\left(t_{2}\right) z^{\prime}\left(t_{2}\right)}{x^{\alpha}\left(t_{2}-\sigma_{1}\right)} \leq-\int_{t_{2}}^{t}\left(p(s)+L_{1} q(s)\right) d s
$$

From condition (2.2), we obtain

$$
\liminf _{t \rightarrow \infty} \frac{a(t) z^{\prime}(t)}{x^{\alpha}\left(t-\sigma_{1}\right)}=-\infty
$$

which contradicts the fact that $z^{\prime}(t) \geq 0$ for all large $t$. This completes the proof of the theorem.

Theorem 2.3 Assume that conditions $\left(\mathrm{H}_{1}\right)$ and $\left(\mathrm{H}_{4}\right)$ hold. Further assume that

$\left(\mathrm{H}_{6}\right) \alpha=\beta$.

If

$$
\limsup _{t \rightarrow \infty} \int_{t_{0}}^{t}(p(s)+q(s)) d s=\infty
$$

then $M^{+}=\emptyset$.

Proof Suppose that equation (1.1) has a solution $x \in M^{+}$. Without loss of generality, we may assume that there exists $t_{1} \geq t_{0}$ such that $x(t)>0$ and $x^{\prime}(t) \geq 0$ for all $t \geq t_{1}$. (The proof is similar if $x(t)<0$ and $x^{\prime}(t) \leq 0$ for large $t$.) Let $z(t)=x(t)+b x\left(t-\tau_{1}\right)+c x\left(t+\tau_{2}\right)$ for $t \geq t_{1}$. Then by assumption $\left(\mathrm{H}_{1}\right)$ we have $z(t)>0$ and $z^{\prime}(t) \geq 0$ for all $t \geq t_{1}$. Now,

$$
\begin{aligned}
\left(\frac{a(t) z^{\prime}(t)}{x^{\alpha}\left(t-\sigma_{1}\right)}\right)^{\prime} & =\frac{\left(a(t) z^{\prime}(t)\right)^{\prime}}{x^{\alpha}\left(t-\sigma_{1}\right)}-\frac{\alpha a(t) z^{\prime}(t) x^{\prime}\left(t-\sigma_{1}\right)}{x^{\alpha+1}\left(t-\sigma_{1}\right)} \\
& \leq-p(t)-q(t) \frac{x^{\alpha}\left(t+\sigma_{2}\right)}{x^{\alpha}\left(t-\sigma_{1}\right)} \\
& \leq-(p(t)+q(t)), \quad t \geq t_{2} \geq t_{1}
\end{aligned}
$$

Integrating the last inequality from $t_{2}$ to $t$, we have

$$
\frac{a(t) z^{\prime}(t)}{x^{\alpha}\left(t-\sigma_{1}\right)}-\frac{a\left(t_{2}\right) z^{\prime}\left(t_{2}\right)}{x^{\alpha}\left(t_{2}-\sigma_{1}\right)} \leq-\int_{t_{2}}^{t}(p(s)+q(s)) d s
$$

From condition (2.3), we obtain

$$
\liminf _{t \rightarrow \infty} \frac{a(t) z^{\prime}(t)}{x^{\alpha}\left(t-\sigma_{1}\right)}=-\infty
$$


which contradicts the fact that $z^{\prime}(t) \geq 0$ for all large $t$. This completes the proof of the theorem.

Theorem 2.4 Assume that conditions $\left(\mathrm{H}_{2}\right)-\left(\mathrm{H}_{4}\right)$ hold. Further assume that

$\left(\mathrm{H}_{7}\right)-1<b+c \leq 0$, with $b<0$ and $c>0$.

If

$$
\int_{t_{0}}^{\infty} \frac{1}{a(s)} d s=\infty \quad \text { and } \quad \int_{t_{0}}^{\infty}(L p(s)+q(s)) d s=\infty
$$

for every $L \geq 0$, then $M^{+}=\emptyset$.

Proof Suppose that equation (1.1) has a solution $x \in M^{+}$. Without loss of generality, we may assume that there exists $t_{1} \geq t_{0}$ such that $x(t)>0$ and $x^{\prime}(t) \geq 0$ for all $t \geq t_{1}$. (The proof if $x(t)<0$ and $x^{\prime}(t) \leq 0$ is similar for large $t$.) Let $z(t)=x(t)+b x\left(t-\tau_{1}\right)+c x\left(t+\tau_{2}\right) \geq$ $(1+b+c) x\left(t-\tau_{1}\right)>0$, for $t \geq t_{1}$. From equation (1.1), we have

$$
\begin{aligned}
\left(a(t) z^{\prime}(t)\right)^{\prime} & =-\left(p(t) \frac{x^{\alpha}\left(t-\sigma_{1}\right)}{x^{\beta}\left(t-\sigma_{2}\right)}+q(t) \frac{x^{\beta}\left(t+\sigma_{2}\right)}{x^{\beta}\left(t-\sigma_{2}\right)}\right) x^{\beta}\left(t-\sigma_{2}\right) \\
& \leq-(L p(t)+q(t)) x^{\beta}\left(t-\sigma_{2}\right) \\
& \leq 0, \quad t \geq t_{1} .
\end{aligned}
$$

Hence, $a(t) z^{\prime}(t)$ is non-increasing for $t \geq t_{1}$, and we claim that $a(t) z^{\prime}(t) \geq 0$ for $t \geq t_{1}$. If $a(t) z^{\prime}(t)<0$ for $t \geq t_{2}$, then $a(t) z^{\prime}(t) \leq a\left(t_{2}\right) z^{\prime}\left(t_{2}\right)<0$ for $t \geq t_{2}>0$. Now,

$$
z^{\prime}(t) \leq \frac{a\left(t_{2}\right) z^{\prime}\left(t_{2}\right)}{a(t)}<0
$$

and integrating the last inequality from $t_{2}$ to $t$, we obtain

$$
z(t)-z\left(t_{2}\right) \leq \int_{t_{2}}^{t} \frac{a\left(t_{2}\right) z^{\prime}\left(t_{2}\right)}{a(s)} d s
$$

This implies that $z(t) \rightarrow-\infty$ as $t \rightarrow \infty$, which is a contradiction. Thus $a(t) z^{\prime}(t) \geq 0$. Now, proceeding as in the proof of Theorem 2.1 and using condition (2.4), we have

$$
\lim _{t \rightarrow \infty} \frac{a(t) z^{\prime}(t)}{x^{\beta}\left(t-\sigma_{2}\right)}=-\infty
$$

This contradicts the fact that $z^{\prime}(t) \geq 0$ for all large $t$. This completes the proof of the theorem.

Theorem 2.5 Assume that conditions $\left(\mathrm{H}_{2}\right),\left(\mathrm{H}_{4}\right),\left(\mathrm{H}_{5}\right)$ and $\left(\mathrm{H}_{7}\right)$ hold. If

$$
\int_{t_{0}}^{\infty} \frac{1}{a(s)} d s=\infty \text { and } \int_{t_{0}}^{\infty}\left(p(s)+L_{1} q(s)\right) d s=\infty
$$

for every $L_{1} \geq 0$, then $M^{+}=\emptyset$. 
Proof The proof is similar to that of Theorem 2.4 and hence the details are omitted.

Theorem 2.6 Assume that conditions $\left(\mathrm{H}_{2}\right),\left(\mathrm{H}_{4}\right),\left(\mathrm{H}_{6}\right)$ and $\left(\mathrm{H}_{7}\right)$ hold. If

$$
\int_{t_{0}}^{\infty} \frac{1}{a(s)} d s=\infty \text { and } \int_{t_{0}}^{\infty}(p(s)+q(s)) d s=\infty
$$

then $M^{+}=\varnothing$.

Proof The proof is similar to that of Theorem 2.4 and hence the details are omitted.

Next, we examine the problem of the existence of solutions of equation (1.1) in the class $M^{-}$.

Theorem 2.7 Assume that conditions $\left(\mathrm{H}_{1}\right)-\left(\mathrm{H}_{3}\right)$ and $\left(\mathrm{H}_{7}\right)$ hold. Further assume that

$\left(\mathrm{H}_{8}\right) \tau_{1} \leq \sigma_{2}$;

$\left(\mathrm{H}_{9}\right) \int_{0}^{\gamma} \frac{d u}{u^{\beta}}<\infty$ and $\int_{-\gamma}^{0} \frac{d u}{u^{\beta}}>-\infty$ for some $\gamma>0$.

If

$$
\limsup _{t \rightarrow \infty} \int_{T}^{t} \frac{1}{a(s)}\left(\int_{T}^{s}(L p(v)+q(v)) d v\right) d s=\infty
$$

for all $T \geq t_{0}$ and for every $L>0$, then $M^{-}=\emptyset$.

Proof Suppose that equation (1.1) has a solution $x \in M^{-}$. Without loss of generality, we may assume that there exists $t_{1} \geq t_{0}$ such that $x(t)>0$ and $x^{\prime}(t) \leq 0$ for all $t \geq t_{1}$. (The proof is similar if $x(t)<0$ and $x^{\prime}(t) \geq 0$ for large $t$.) Let $z(t)=x(t)+b x\left(t-\tau_{1}\right)+c x\left(t+\tau_{2}\right)$, then in view of $\left(\mathrm{H}_{1}\right), z(t)>0$ and $z^{\prime}(t) \leq 0$ for all $t \geq t_{1}$. As in the proof of Theorem 2.1, we obtain

$$
\frac{a(t) z^{\prime}(t)}{x^{\beta}\left(t-\sigma_{2}\right)}-\frac{a\left(t_{1}\right) z^{\prime}\left(t_{1}\right)}{x^{\beta}\left(t_{1}-\sigma_{2}\right)} \leq-\int_{t_{1}}^{t}(L p(s)+q(s)) d s, \quad t \geq t_{1}
$$

or

$$
\frac{z^{\prime}(t)}{x^{\beta}\left(t-\sigma_{2}\right)} \leq \frac{-1}{a(t)} \int_{t_{1}}^{t}(L p(s)+q(s)) d s, \quad t \geq t_{1}
$$

Since $x$ is non-increasing and by $\left(\mathrm{H}_{8}\right)$, we see that $z(t) \leq(1+b+c) x\left(t-\sigma_{2}\right) \geq 0$ and

$$
z^{\beta}(t) \leq(1+b+c)^{\beta} x^{\beta}\left(t-\sigma_{2}\right)
$$

Combining (2.8) and (2.9), we have

$$
\begin{aligned}
\frac{z^{\prime}(t)}{z^{\beta}(t)} & \leq \frac{z^{\prime}(t)}{(1+b+c)^{\beta} x^{\beta}\left(t-\sigma_{2}\right)} \\
& \leq \frac{-1}{a(t)(1+b+c)^{\beta}} \int_{t_{1}}^{t}(L p(s)+q(s)) d s, \quad t \geq t_{1} .
\end{aligned}
$$


Integrating the last inequality from $t_{1}$ to $t$, yields

$$
\int_{z\left(t_{1}\right)}^{z(t)} \frac{d s}{s^{\beta}} \leq-\int_{t_{1}}^{t} \frac{1}{a(s)(1+b+c)^{\beta}}\left(\int_{t_{1}}^{s}(L p(v)+q(v)) d v\right) d s
$$

or

$$
\int_{z(t)}^{z\left(t_{1}\right)} \frac{d s}{s^{\beta}} \geq \int_{t_{1}}^{t} \frac{1}{a(s)(1+b+c)^{\beta}}\left(\int_{t_{1}}^{s}(L p(v)+q(v)) d v\right) d s
$$

and by condition (2.7) we see that

$$
\limsup _{t \rightarrow \infty} \int_{z(t)}^{z\left(t_{1}\right)} \frac{d s}{s^{\beta}}=\infty
$$

which contradicts condition $\left(\mathrm{H}_{9}\right)$. This completes the proof of the theorem.

Theorem 2.8 Assume that conditions $\left(\mathrm{H}_{1}\right),\left(\mathrm{H}_{4}\right),\left(\mathrm{H}_{5}\right)$ and $\left(\mathrm{H}_{7}\right)$ hold. Further assume that

$\left(\mathrm{H}_{10}\right) \tau_{1} \leq \sigma_{1}$

$\left(\mathrm{H}_{11}\right) \int_{0}^{\gamma} \frac{d u}{u^{\alpha}}<\infty$ and $\int_{-\gamma}^{0} \frac{d u}{u^{\alpha}}>-\infty$, for some $\gamma>0$.

If

$$
\limsup _{t \rightarrow \infty} \int_{T}^{t} \frac{1}{a(s)}\left(\int_{T}^{s}\left(p(v)+L_{1} q(v)\right) d v\right) d s=\infty
$$

for all $T \geq t_{0}$ and for every $L_{1}>0$, then $M^{-}=\emptyset$.

Proof Suppose that equation (1.1) has a solution $x \in M^{-}$. Without loss of generality, we may assume that there exists $t_{1} \geq t_{0}$ such that $x(t)>0$ and $x^{\prime}(t) \leq 0$ for all $t \geq t_{1}$. (The proof is similar if $x(t)<0$ and $x^{\prime}(t) \geq 0$ for all large $t$.) Let $z(t)=x(t)+b x\left(t-\tau_{1}\right)+c x\left(t+\tau_{2}\right)$, then in view of $\left(\mathrm{H}_{1}\right), z(t)>0$ and $z^{\prime}(t) \leq 0$ for all $t \geq t_{1}$. As in the proof of Theorem 2.2, we obtain the inequality

$$
\frac{a(t) z^{\prime}(t)}{x^{\alpha}\left(t-\sigma_{1}\right)}-\frac{a\left(t_{1}\right) z^{\prime}\left(t_{1}\right)}{x^{\alpha}\left(t_{1}-\sigma_{1}\right)} \leq-\int_{t_{1}}^{t}\left(p(s)+L_{1} q(s)\right) d s, \quad t \geq t_{1}
$$

or

$$
\frac{z^{\prime}(t)}{x^{\alpha}\left(t-\sigma_{1}\right)} \leq \frac{-1}{a(t)} \int_{t_{1}}^{t}\left(p(s)+L_{1} q(s)\right) d s, \quad t \geq t_{0}
$$

Since $x$ is non-increasing and by $\left(\mathrm{H}_{10}\right)$, we see that $z(t) \leq(1+b+c) x\left(t-\sigma_{1}\right) \geq 0$ and then

$$
z^{\alpha}(t) \leq(1+b+c)^{\alpha} x^{\alpha}\left(t-\sigma_{1}\right)
$$

Combining (2.12) and (2.13), we have

$$
\begin{aligned}
\frac{z^{\prime}(t)}{z^{\alpha}(t)} & \leq \frac{z^{\prime}(t)}{(1+b+c)^{\alpha} x^{\alpha}\left(t-\sigma_{1}\right)} \\
& \leq \frac{-1}{a(t)(1+b+c)^{\alpha}} \int_{t_{1}}^{t}\left(p(s)+L_{1} q(s)\right) d s, \quad t \geq t_{1} .
\end{aligned}
$$


The rest of the proof is similar to that of Theorem 2.7 and hence the details are omitted. This completes the proof of the theorem.

Theorem 2.9 Assume that conditions $\left(\mathrm{H}_{1}\right),\left(\mathrm{H}_{4}\right),\left(\mathrm{H}_{6}\right),\left(\mathrm{H}_{7}\right),\left(\mathrm{H}_{10}\right)$ and $\left(\mathrm{H}_{11}\right)$ hold. If

$$
\limsup _{t \rightarrow \infty} \int_{T}^{t} \frac{1}{a(s)}\left(\int_{T}^{s}(p(v)+q(v)) d v\right) d s=\infty
$$

for all $T \geq t_{0}$, then $M^{-}=\emptyset$.

Proof The proof is similar to that of Theorem 2.8 and hence the details are omitted.

Next, we establish sufficient conditions under which any solution of equation (1.1) is either oscillatory or weakly oscillatory.

Theorem 2.10 If conditions $\left(\mathrm{H}_{1}\right),\left(\mathrm{H}_{2}\right),\left(\mathrm{H}_{3}\right),\left(\mathrm{H}_{4}\right)$ and $(2.4)$ hold, then every solution of equation (1.1) is either oscillatory or weakly oscillatory.

Proof From Theorem 2.1, it follows that for equation (1.1) we have $M^{+}=\emptyset$. To complete the proof, it suffices to show that for equation (1.1), $M^{-}=\emptyset$. Let $x$ be a solution of equation (1.1) belonging to the class $M^{-}$, say that $x(t)>0$ and $x^{\prime}(t) \leq 0$ for $t \geq t_{1} \geq t_{0}$. (The proof is similar if $x(t)<0$ and $x^{\prime}(t) \geq 0$ for all large $t$.) Let $z(t)=x(t)+b x\left(t-\tau_{1}\right)+c x\left(t+\tau_{2}\right)$; then in view of $\left(\mathrm{H}_{1}\right)$, we have $z(t)>0$ and $z^{\prime}(t) \leq 0$ for all $t \geq t_{1}$. Proceeding as in the proof of Theorem 2.1, we obtain

$$
\frac{a(t) z^{\prime}(t)}{x^{\beta}\left(t-\sigma_{2}\right)}-\frac{a\left(t_{1}\right) z^{\prime}\left(t_{1}\right)}{x^{\beta}\left(t_{1}-\sigma_{2}\right)}+\int_{t_{1}}^{t} \frac{\beta a(s) z^{\prime}(s) x^{\prime}\left(s-\sigma_{2}\right)}{x^{\beta+1}\left(s-\sigma_{2}\right)} d s \leq-\int_{t_{1}}^{t}(L p(s)+q(s)) d s .
$$

Set

$$
w(t)=\frac{a(t) z^{\prime}(t)}{x^{\beta}\left(t-\sigma_{2}\right)}, \quad t \geq t_{1}
$$

Then $w(t)<0$ and for $t \geq t_{1}$,

$$
w^{\prime}(t)=\frac{\left(a(t) z^{\prime}(t)\right)^{\prime}}{x^{\beta}\left(t-\sigma_{2}\right)}-\beta \frac{a(t) z^{\prime}(t)}{x^{\beta+1}\left(t-\sigma_{2}\right)} x^{\prime}\left(t-\sigma_{2}\right) \leq-(L p(t)+q(t))-\beta w(t) \frac{x^{\prime}\left(t-\sigma_{2}\right)}{x\left(t-\sigma_{2}\right)} .
$$

Integrating the last inequality from $t_{1}$ to $t$ and using condition (2.4), we have

$$
w(t) \leq w\left(t_{1}\right)+\int_{t_{1}}^{t} w(s)\left(-\beta \frac{x^{\prime}\left(s-\sigma_{2}\right)}{x\left(s-\sigma_{2}\right)}\right) d s, \quad t \geq t_{2} \geq t_{1} .
$$

By Gronwall's inequality, we obtain

$$
w(t) \leq w\left(t_{1}\right)\left(\frac{x\left(t_{1}-\sigma_{2}\right)}{x\left(t-\sigma_{2}\right)}\right)^{\beta}
$$

and so

$$
a(t) z^{\prime}(t) \leq w\left(t_{1}\right) x^{\beta}\left(t_{1}-\sigma_{2}\right)=M_{1}<0
$$




$$
z^{\prime}(t) \leq \frac{M_{1}}{a(t)}, \quad t \geq t_{2}
$$

The integration yields

$$
z(t) \leq z\left(t_{2}\right)+M_{1} \int_{t_{2}}^{t} \frac{1}{a(s)} d s \rightarrow-\infty
$$

as $t \rightarrow \infty$ by condition (2.4). This contradiction completes the proof.

Theorem 2.11 If conditions $\left(\mathrm{H}_{1}\right),\left(\mathrm{H}_{4}\right),\left(\mathrm{H}_{5}\right)$ and $(2.5)$ hold, then every solution of equation (1.1) is either oscillatory or weakly oscillatory.

Proof The proof is similar to that of Theorem 2.10 and hence the details are omitted.

Theorem 2.12 If conditions $\left(\mathrm{H}_{1}\right),\left(\mathrm{H}_{4}\right),\left(\mathrm{H}_{6}\right)$ and (2.6) hold, then every solution of equation (1.1) is either oscillatory or weakly oscillatory.

Proof The proof is similar to that of Theorem 2.10 and hence the details are omitted.

\section{Behavior of solutions in the classes $M^{+}$and $M^{-}$}

First, we study the asymptotic behavior of solutions in the class $M^{-}$.

Theorem 3.1 Assume that conditions $\left(\mathrm{H}_{1}\right)-\left(\mathrm{H}_{3}\right)$ and $\left(\mathrm{H}_{8}\right)$ hold. If condition (2.7) holds, then for every solution $x(t) \in M^{-}$, we have $\lim _{t \rightarrow \infty} x(t)=0$.

Proof The argument used in the proof of Theorem 2.7 again leads to (2.10). This implies that $\lim _{t \rightarrow \infty} z(t)=0$. But $z(t) \geq x(t)$ for all $t \geq t_{1}$ implies that $\lim _{t \rightarrow \infty} x(t)=0$ and the proof is complete.

Theorem 3.2 Assume that conditions $\left(\mathrm{H}_{1}\right),\left(\mathrm{H}_{4}\right),\left(\mathrm{H}_{5}\right)$ and $\left(\mathrm{H}_{10}\right)$ hold. If condition (2.11) holds, then for every solution $x(t) \in M^{-}$, we have $\lim _{t \rightarrow \infty} x(t)=0$.

Proof The argument used in the proof of Theorem 2.8 again leads to (2.14). This implies that $\lim _{t \rightarrow \infty} z(t)=0$. But $z(t) \geq x(t)$ for all $t \geq t_{1}$ implies that $\lim _{t \rightarrow \infty} x(t)=0$ and the proof is complete.

Theorem 3.3 Assume that conditions $\left(\mathrm{H}_{1}\right),\left(\mathrm{H}_{4}\right),\left(\mathrm{H}_{6}\right)$ and $\left(\mathrm{H}_{10}\right)$ hold. If condition (2.14) holds, then for every solution $x(t) \in M^{-}$, we have $\lim _{t \rightarrow \infty} x(t)=0$.

Proof The argument used in the proof of Theorem 2.8 again leads to (2.14). This implies that $\lim _{t \rightarrow \infty} z(t)=0$. But $z(t) \geq x(t)$ for all $t \geq t_{1}$ implies that $\lim _{t \rightarrow \infty} x(t)=0$ and the proof is complete.

Finally, we examine the asymptotic behavior of solutions in the class $M^{+}$. 
Theorem 3.4 If the assumptions $\left(\mathrm{H}_{1}\right)-\left(\mathrm{H}_{3}\right)$ hold and

$$
\limsup _{t \rightarrow \infty} \int_{T}^{t}(L p(s)+q(s))\left(\int_{T}^{s} \frac{1}{a(v)} d v\right) d s=\infty
$$

for all $T \geq t_{0}$, and any $L>0$ is satisfied, then every solution in the class $M^{+}$is unbounded.

Proof Let $x$ be a solution of equation (1.1) such that $x \in M^{+}$. Without loss of generality, we assume that there exists $t_{1} \geq t_{0}$ such that $x(t)>0$ and $x^{\prime}(t)>0$ for all $t \geq t_{1}$, for some $t_{1} \geq t_{0}$. (The proof is similar if $x(t)<0$ and $x^{\prime}(t) \leq 0$ for all large $t$.) Let $z(t)=x(t)+b x(t-$ $\left.\tau_{1}\right)+c x\left(t+\tau_{2}\right)$; then in view of condition $\left(\mathrm{H}_{1}\right), z(t)>0$ and $z^{\prime}(t) \geq 0$ for all $t \geq t_{1}$. Consider the function

$$
w(t)=-\frac{a(t) z^{\prime}(t)}{x^{\beta}\left(t-\sigma_{2}\right)} \int_{t_{1}}^{t} \frac{1}{a(s)} d s, \quad t \geq t_{2} \geq t_{1} .
$$

Then we have for $t \geq t_{2}$

$$
\begin{aligned}
w^{\prime}(t) & =-\frac{z^{\prime}(t)}{x^{\beta}\left(t-\sigma_{2}\right)}-\frac{\left(a(t) z^{\prime}(t)\right)^{\prime}}{x^{\beta}\left(t-\sigma_{2}\right)} \int_{t_{1}}^{t} \frac{1}{a(s)} d s+\frac{\beta a(t) z^{\prime}(t) x^{\prime}\left(t-\sigma_{2}\right)}{x^{\beta+1}\left(t-\sigma_{2}\right)} \int_{t_{1}}^{t} \frac{1}{a(s)} d s \\
& \geq-\frac{z^{\prime}(t)}{x^{\beta}\left(t-\sigma_{2}\right)}+(L p(s)+q(s)) \int_{t_{1}}^{t} \frac{1}{a(s)} d s .
\end{aligned}
$$

Integrating the last inequality, we obtain

$$
w(t) \geq w\left(t_{2}\right)+\int_{t_{2}}^{t}(L p(s)+q(s))\left(\int_{t_{1}}^{s} \frac{1}{a(v)} d v\right) d s-\int_{t_{2}}^{t} \frac{z^{\prime}(s)}{x^{\beta}\left(s-\sigma_{2}\right)} d s .
$$

As the function $\frac{z^{\prime}(t)}{x^{\beta}\left(t-\sigma_{2}\right)}$ is positive for $t>t_{2}$, then the limit $\lim _{t \rightarrow \infty} \int_{t_{2}}^{t} \frac{z^{\prime}(s)}{x^{\beta}\left(s-\sigma_{2}\right)} d s$ exists. We claim that it is $\infty$. Assume that

$$
\lim _{t \rightarrow \infty} \int_{t_{2}}^{t} \frac{z^{\prime}(s)}{x^{\beta}\left(s-\sigma_{2}\right)} d s=M_{4}<\infty
$$

In view of (3.1) and (3.2), we have $\limsup _{t \rightarrow \infty} w(t)=\infty$, which contradicts $w(t)$ being negative for all large values of $t$. Thus

$$
\lim _{t \rightarrow \infty} \int_{t_{2}}^{t} \frac{z^{\prime}(s)}{x^{\beta}\left(s-\sigma_{2}\right)} d s=\infty
$$

Now, for all values of $t \geq t_{2}$, we have $x^{\beta}\left(t-\sigma_{2}\right) \geq x^{\beta}\left(t_{1}-\sigma_{2}\right)$, or $\frac{1}{x^{\beta}\left(t-\sigma_{2}\right)} \leq \frac{1}{x^{\beta}\left(t_{1}-\sigma_{2}\right)}=M_{5}$, and consequently

$$
\begin{aligned}
\int_{t_{2}}^{t} \frac{z^{\prime}(s)}{x^{\beta}\left(t-\sigma_{2}\right)} d s & \leq M_{5} \int_{t_{2}}^{t} z^{\prime}(s) d s \\
& =M_{5}\left(z(t)-z\left(t_{2}\right)\right)
\end{aligned}
$$

From (3.3) we obtain

$$
\lim _{t \rightarrow \infty} z(t)=\infty .
$$


Since $z(t)=x(t)+b x\left(t-\tau_{1}\right)+c x\left(t+\tau_{2}\right)$ and $x(t)$ is nondecreasing, we have $z(t) \leq(1+b+$ $c) x\left(t+\tau_{2}\right)$. In view of (3.4) we get $\lim _{t \rightarrow \infty} x(t)=\infty$. This completes the proof.

Theorem 3.5 If the assumptions $\left(\mathrm{H}_{1}\right),\left(\mathrm{H}_{4}\right)$ and $\left(\mathrm{H}_{5}\right)$ hold and

$$
\limsup _{t \rightarrow \infty} \int_{T}^{t}\left(p(s)+L_{1} q(s)\right)\left(\int_{T}^{s} \frac{1}{a(v)} d v\right) d s=\infty
$$

for all $T \geq t_{0}$, and for any $L_{1}>0$ is satisfied, then every solution in the class $M^{+}$is unbounded.

Proof The proof is similar to that of Theorem 3.4 and hence the details are omitted.

Theorem 3.6 If the assumptions $\left(\mathrm{H}_{1}\right),\left(\mathrm{H}_{4}\right)$ and $\left(\mathrm{H}_{6}\right)$ hold and

$$
\limsup _{t \rightarrow \infty} \int_{T}^{t}(p(s)+q(s))\left(\int_{T}^{s} \frac{1}{a(v)} d v\right) d s=\infty
$$

for all $T \geq t_{0}$ is satisfied, then every solution in the class $M^{+}$is unbounded.

Proof The proof is similar to that of Theorem 3.4 and hence the details are omitted.

\section{Examples}

In this section we present some examples to illustrate the main results.

Example 1 Consider the differential equation

$$
\left(\frac{1}{t}(x(t)+2 x(t-1)+3 x(t+1))^{\prime}\right)^{\prime}+\frac{1}{t^{2}(t-1)^{3}} x^{3}(t-1)+\frac{5}{t^{2}(t+1)} x(t+1)=0
$$

for $t \geq 2$. All the conditions of Theorem 2.1 are satisfied except condition (2.1). We see that equation (4.1) has a solution $x(t)=t \in M^{+}$since it satisfies equation (4.1).

Example 2 Consider the differential equation

$$
\left(\frac{1}{t}(x(t)+4 x(t-2)+5 x(t+1))^{\prime}\right)^{\prime}+\frac{4}{t^{2}(t-1)} x(t-1)+\frac{6}{t^{2}(t+2)^{3}} x^{3}(t+2)=0
$$

for $t \geq 2$. All the conditions of Theorem 2.2 are satisfied except condition (2.2). We see that equation (4.2) has a solution $x(t)=t \in M^{+}$since it satisfies equation (4.2).

Example 3 Consider the differential equation

$$
\left(\frac{1}{t}(x(t)+x(t-1)+x(t+1))^{\prime}\right)^{\prime}+\frac{1}{t^{2}(t-1)^{3}} x^{3}(t-1)+\frac{2}{t^{2}(t+1)^{3}} x^{3}(t+1)=0
$$

for $t \geq 2$. All the conditions of Theorem 2.3 are satisfied except condition (2.3). We see that equation (4.3) has a solution $x(t)=t \in M^{+}$since it satisfies equation (4.3). 
Example 4 Consider the differential equation

$$
\left(t^{2}(x(t)-3 x(t-1)+x(t+1))^{\prime}\right)^{\prime}+\frac{t}{(t-1)} x(t-1)+\frac{t}{(t+2)^{3}} x^{3}(t+2)=0
$$

for $t \geq 2$. All the conditions of Theorem 2.5 are satisfied except conditions $\left(\mathrm{H}_{7}\right)$ and (2.5). In fact, it has a solution $x(t)=t \in M^{+}$.

Example 5 Consider the differential equation

$$
\left(e^{2 t}\left(x(t)+\frac{1}{e} x(t-1)+e x(t+1)\right)^{\prime}\right)^{\prime}+e^{4 t-6} x^{3}(t-2)+2 e^{2 t+3} x(t+3)=0
$$

for $t \geq 0$. Since the function $x(t)=e^{-t}$ is a solution of equation (4.5), we have $M^{-} \neq \emptyset$. Moreover, condition (2.7) holds in Theorem 2.7, while condition $\left(\mathrm{H}_{9}\right)$ is not satisfied.

Example 6 Consider the differential equation

$$
\left(e^{2 t}\left(x(t)+\frac{1}{e} x(t-1)+e^{2} x(t+2)\right)^{\prime}\right)+e^{\frac{2}{3}(2 t-1)} x^{\frac{1}{3}}(t-2)+2 e^{2 t+3} x(t+3)=0
$$

for $t \geq 0$. Since the function $x(t)=e^{-t}$ is a solution of equation (4.6), we have $M^{-} \neq \emptyset$. For this equation condition (2.11) does not hold in Theorem 2.8, while condition $\left(\mathrm{H}_{10}\right)$ is satisfied.

Example 7 Consider the differential equation (4.5). It is easy to see that all the conditions of Theorem 3.2 are satisfied. In fact, $x(t)=e^{-t} \in M^{-}$is a solution of equation (4.5) such that $x(t)=e^{-t} \rightarrow 0$ as $t \rightarrow \infty$.

Example 8 Consider the differential equation (4.3). It can easily be seen that all the conditions of Theorem 3.4 are satisfied. Here $x(t)=t \in M^{+}$is a solution of equation (4.3) such that $x(t) \rightarrow \infty$ as $t \rightarrow \infty$.

We conclude this paper with the following remark.

Remark 1 In this paper we obtained conditions for the non-existence of solutions in the classes $M^{+}$and $M^{-}$and the existence of solutions in the classes OS and WOS. It would be interesting to extend the results of this paper to the following equation:

$$
\left(a(t)\left(x(t)+b(t) x\left(t-\tau_{1}\right)+c(t) x\left(t+\tau_{2}\right)\right)^{\prime}\right)^{\prime}+p(t) x^{\alpha}\left(t-\sigma_{1}\right)+q(t) x^{\beta}\left(t+\sigma_{2}\right)=r(t),
$$

where $r(t)$ is a real valued continuous function. 


\section{Author details}

${ }^{1}$ Ramanujan Institute for Advanced Study in Mathematics, University of Madras, Chennai, 600005 , India. ${ }^{2}$ Departamento de Ciências Exactas e Naturais, Academia Militar, Av. Conde Castro Guimarães, Amadora, 2720-113, Portugal.

Received: 23 November 2012 Accepted: 3 December 2012 Published: 28 December 2012

\section{References}

1. Driver, RD: A mixed neutral system. Nonlinear Anal. 8, 155-158 (1994)

2. Hale, JK: Theory of Functional Differential Equations. Springer, New York (1977)

3. Thandapani, E, Maria Susai Manuel, M: Oscillatory and non-oscillatory behaviour of second order neutral delay differential equations. Eng. Simul. 15, 159-167 (1998)

4. Thandapani, E, Muthulakshmi, V, Grafe, JR: Classifications of solutions of second order nonlinear neutral delay differential equations with positive and negative coefficients. Int. J. Pure Appl. Math. 64, 159-170 (2010)

5. Bainov, DD, Mishev, DP: Oscillation Theory for Neutral Differential Equations with Delay. Hilger, New York (1991)

6. Erbe, LH, Kong, Q, Zhang, BG: Oscillation Theory for Functional Differential Equations. Dekker, New York (1994)

7. Ladde, GS, Lakshmikantham, V, Zhang, BG: Qualitative Theory of Differential Equations with Deviating Arguments. Pure Appl. Maths., vol. 110. Dekker, New York (1987)

8. Cecchi, M, Marini, M: Oscillatory and nonoscillatory behavior of a second order functional differential equations. Rocky Mt. J. Math. 22, 1259-1276 (1992)

9. Dzurina, J, Busa, J, Airyan, EA: Oscillation criteria for second order differential equations of neutral type with mixed arguments. Differ. Equ. 38, 126-128 (2002)

10. Grace, SR: On the oscillations of mixed neutral equations. J. Math. Anal. Appl. 194, 377-388 (1995)

11. Grace, SR: Oscillations of mixed neutral functional differential equations. Appl. Math. Comput. 68, 1-13 (1995)

12. Gyori, I, Ladas, G: Oscillation Theory of Delay Differential Equations with Applications. Clarendon, Oxford (1991)

doi:10.1186/1687-1847-2012-226

Cite this article as: Thandapani et al.: Classifications of solutions of second-order nonlinear neutral differential equations of mixed type. Advances in Difference Equations 2012 2012:226.

\section{Submit your manuscript to a SpringerOpen ${ }^{\odot}$ journal and benefit from:}

- Convenient online submission

- Rigorous peer review

- Immediate publication on acceptance

Open access: articles freely available online

- High visibility within the field

- Retaining the copyright to your article 